\title{
CRIAÇÃO, APLICAÇÃO E AVALIAÇÃO DE UM SOFTWARE EDUCATIVO PARA CRIANÇAS COM SÍNDROME DE DOWN
}

Elaine Pasqualini, Eunice Correa S. Belotti, Bruno Severino Martins, Felipe Rafael Rosa, Guilherme Ribeiro Sartori

Resumo

De acordo com a literatura brasileira há escassez de softwares educativos para crianças com Síndrome de Down. O objetivo desse trabalho foi criar, aplicar e avaliar um software educativo que ensine as vogais para essas crianças. A pesquisa foi realizada na Associação de Pais e Amigos dos Excepcionais (APAE) em uma cidade do interior do Estado de São Paulo com 28 professores. Profissionais da APAE auxiliaram na criação do roteiro do software por meio de entrevistas e foi definida a apresentação das vogais com 5 jogos diferentes e a codificação foi feita em Flash. No dia da aplicação, o software foi instalado nos computadores e os participantes assinaram o termo de consentimento, usaram o programa e responderam um questionário com 11 questões objetivas e uma dissertativa. O resultado apontou que $92,86 \%$ dos professores acharam que o programa apresentou instruções claras e $100 \%$ responderam ter facilidade de navegação e que os jogos foram mostrados de forma lúdica. Descreveram que não é aconselhável apresentar as vogais minúsculas, 46,67\%. Conclui-se pelos relatos dos professores que o software pode servir de apoio para as aulas dos professores.

Palavras-chave: Software educativo. Síndrome de Down. Vogais.

\section{CREATION, APPLICATION AND EVALUATION OF EDUCATIONAL SOFTWARE FOR CHILDREN WITH DOWN SINDROME}

\begin{abstract}
According to the Brazilian literature, there is a scarcity of educational software for children with Down Syndrome. The aim of this essay was to create, apply and evaluate educational software that teaches the vowels to these children. The research was performed in the Association of Parents and Friends of Exceptional Children (APAE) in a city in the State of São Paulo with 28 teachers. APAE professionals have helped in the creation of the software script through the use of interviews. The presentation of the vowels with 5 different games was defined, and the codification was developed in Flash. On the day of the application, the software was installed in the computers. The participants signed the term of consent, used the program, and answered a questionnaire with eleven multiple choice questions and a written one. The results showed that $92,86 \%$ of the teachers found that the program had clear instructions and $100 \%$ answered that it has an easy navigation and that the games were shown in a ludic way. $46,67 \%$ of the teachers have also described that it is not advisable to present the lowercase letters. According to the teachers' reports, we have concluded that the software may support their classes.
\end{abstract}

Keywords: Educational Software. Down Sindrome. Vowels.

\section{Introdução}


As crianças com Síndrome de Down apresentam limitações físicas, intelectuais e sociais, que podem ser melhoradas por meio de intervenções eficazes (Rodrigues; Santos; Carlino, 2014).

No aspecto intelectual, de acordo com Cerro (2006), indivíduos com Síndrome de Down têm capacidade para ler e falar, sendo que este processo tem seu próprio ritmo e tempo e a aprendizagem pode ocorrer lentamente.

Para Amaral e Gomedi (2004) a criança Down não se concentra o tempo suficiente para guardar as informações, comparado a outras crianças sem esse problema.

Para Bissoto (2005), as escolas devem procurar metodologias para superação das dificuldades, como por exemplo, utilizar demonstrações e recursos visuais para facilitar a aprendizagem.

Assim sendo, uma das possibilidades é o uso de softwares educativos, que são programas de computador desenvolvidos para atender aos objetivos educacionais estabelecidos, com o apoio de imagens, textos, animações, etc. (Valente, 1993).

De acordo com a literatura brasileira investigada há escassez de trabalhos nessa área. O trabalho de Araújo, Brito e Silva (2013) descreve uma revisão sistemática na literatura em trabalhos publicados de 2001 a 2012 no Simpósio Brasileiro de Informática na Educação e no Workshop de Informática na Escola, eventos de referência nacional que divulgam a produção científica na área de Informática na Educação. Foram encontrados apenas 2 softwares educativos destinados às crianças com Síndrome de Down: Software para ensino de inglês com foco na interface amigável para portadores de Síndrome de Down e Software com o propósito de estimular a aprendizagem da prática de leitura e escrita em língua portuguesa de crianças.

Dessa forma, o objetivo desse trabalho foi criar, aplicar e avaliar um software educativo que ensine as vogais para crianças com Síndrome de Down.

\section{Método}

Descreve-se o ambiente, os participantes, os instrumentos e os procedimentos para se atingir os objetivos propostos.

Ambiente

A pesquisa foi realizada na Associação de Pais e Amigos dos Excepcionais (APAE) em uma cidade do interior do Estado de São Paulo com cerca de 110.000 habitantes. Mais especificamente, foi utilizado o laboratório de informática da instituição.

\section{Participantes}

Para o desenvolvimento do software educativo os próprios autores do projeto, criaram, e na aplicação, 28 professores da APAE utilizaram o sistema. Desses professores, $92,86 \%$ (26) eram do sexo feminino e com experiência na área especial de 0 a 4,9 anos, 46,43\% (13); de 5,0 a 9,9 anos, 14,29\% (4); de 10 a 14,99 anos, 21,43\% (6); de 15 a 19,9 anos, 10,71\% (3) e acima de $15,7,14 \%$ (2).

Materiais e Instrumentos

- ferramenta Flash CS5 e a linguagem Action Script para a criação do software;

- termo de consentimento livre e esclarecido;

- laboratório de informática com seus computadores;

- internet com qualquer navegador para acessar o software;

- software educativo desenvolvido;

- questionário qualitativo elaborado para avaliação do software; 
- planilha eletrônica para computar as respostas do questionário.

Procedimentos

Criação do software

O projeto teve início pelo contato estabelecido com profissionais que trabalham com o ensino de crianças com Síndrome de Down. Duas psicólogas da APAE auxiliaram a criação do roteiro do software por meio de entrevistas. Uma das preocupações relatadas era manter a criança envolvida com a aplicação, com o uso de botões com cores para chamar a atenção e sons. Também foi citada a necessidade desse software possuir atividades rápidas, visto que as demoradas poderiam fazer com que a criança perdesse o foco na atividade. Outro item questionado às psicólogas foi o fato da melhor forma de informar a criança de que uma atividade/questão que ela respondesse estaria incorreta. Elas comentaram que seria importante a criança ser condicionada para chegar à resposta correta. Após entrevistas para identificar as necessidades, escolheu-se trabalhar apenas com as vogais. O roteiro foi definido com a apresentação das vogais maiúsculas e minúsculas e foram criados 5 jogos para facilitar a aprendizagem. Foram utilizados os princípios de desenvolvimento e qualidade de Engenharia de Software, sendo desenvolvida a documentação do software e do roteiro. A codificação foi feita em Action Script, com o uso da ferramenta Flash. Na última etapa da criação foram aplicados testes para verificar se o programa apresentava erros de codificação e foram feitos pelos autores do projeto.

Aplicação

Foi marcado o dia da aplicação do software com os participantes e eles concordaram e assinaram o termo de consentimento. O tempo de duração total foi de 1 hora. Primeiramente o software foi instalado e testado em todos os computadores. Foi explicado o objetivo da aplicação e do programa. Após isso, cada professor usou o software e respondeu o questionário.

Avaliação

Foi criado um questionário qualitativo com 11 questões objetivas e uma dissertativa. Esse instrumento de avaliação foi elaborado com base nos trabalhos de Cenci e Bonelli (2012) e Vieira (2012). Para que fosse possível avaliar a ação educativa foram gerados relatórios das respostas dos professores, por meio de uma planilha eletrônica.

\section{Resultados}

Software desenvolvido

O programa criado, denominado Saber, trabalha com as vogais do alfabeto de maneira repetitiva, porém utiliza 5 jogos diferentes. Para Silva (1998), o jogo é um meio lúdico e pode ser um auxílio eficaz no processo de ensino e aprendizagem.

Com o jogo é possível desenvolver a parte motora e cognitiva da criança melhorando algumas habilidades, como a coordenação motora fina, a descoberta, a observação, a análise, a criatividade, entre outras (Amaral; Gomedi, 2004).

Este software procurou reforçar a aprendizagem da criança com Síndrome de Down, explorando, além do conhecimento das vogais, a coordenação motora fina, percepção, manuseio com o computador, etc. 
Para Soares (2002) e Kirk e Gallagher (1991) há necessidade de ser usar técnicas de desenvolvimento de jogos para as necessidades dessas crianças, como cores e organização do conteúdo.

Cada botão foi definido com uma cor específica de acordo com a função, como o verde para começar o jogo, laranja para sair, etc.

O conteúdo foi organizado colocando-se tarefas mais simples, aumentando gradativamente o grau de dificuldade.

O jogo tem apenas uma personagem feminina com o nome de Lalá com características físicas de uma criança com Síndrome de Down. Ela fala em todas as telas para explicar as atividades. A interface tem característica de uma sala de aula e outros objetos do ambiente escolar. Na tela inicial, a personagem fala sobre o conteúdo e uma breve ajuda referente aos botões utilizados. Após isso, é disponibilizado um botão para dar início às atividades. Cada atividade sempre é iniciada com uma fala para dar uma explicação geral.

A Figura 1 exibe o menu inicial do software com as opções de entrar e sair.

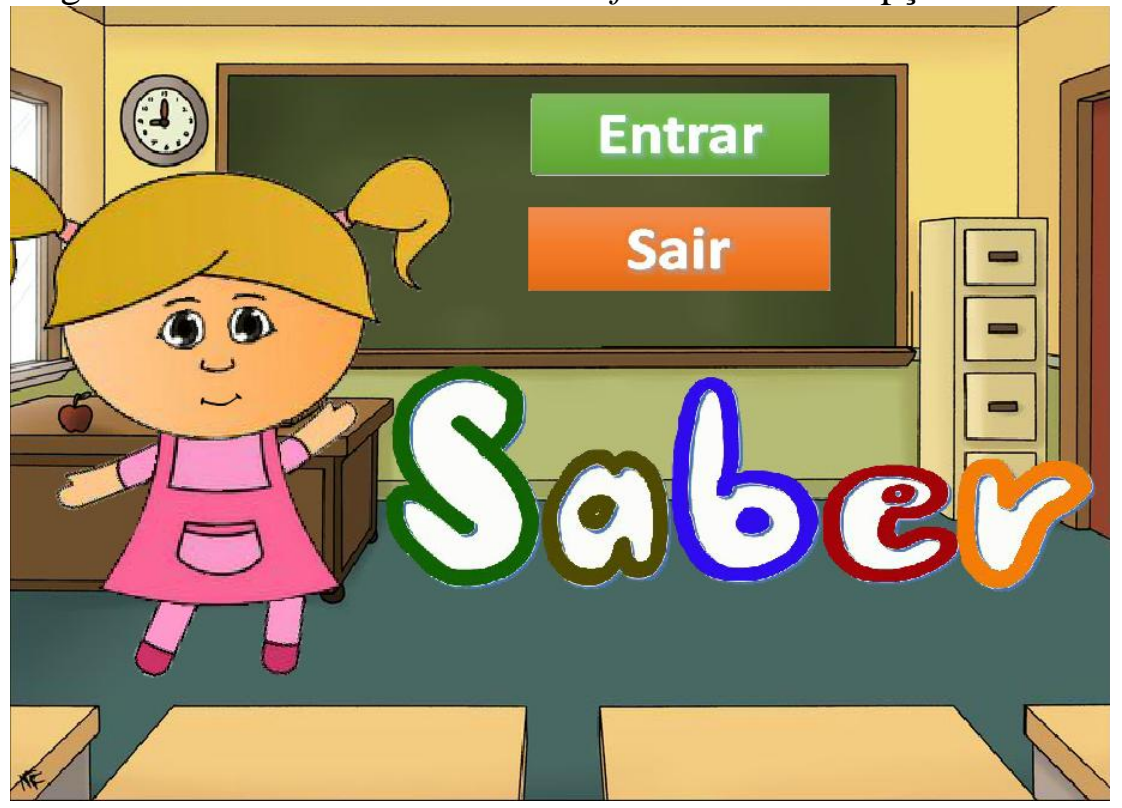

Figura 1 - Tela de Abertura do software

Ao escolher o botão Entrar, o programa exibe as vogais maiúsculas primeiramente e depois as minúsculas. Após apresenta-se as vogais maiúsculas e minúsculas juntas, como mostra a Figura 2. 


CINTED-UFRGS Novas Tecnologias na Educação

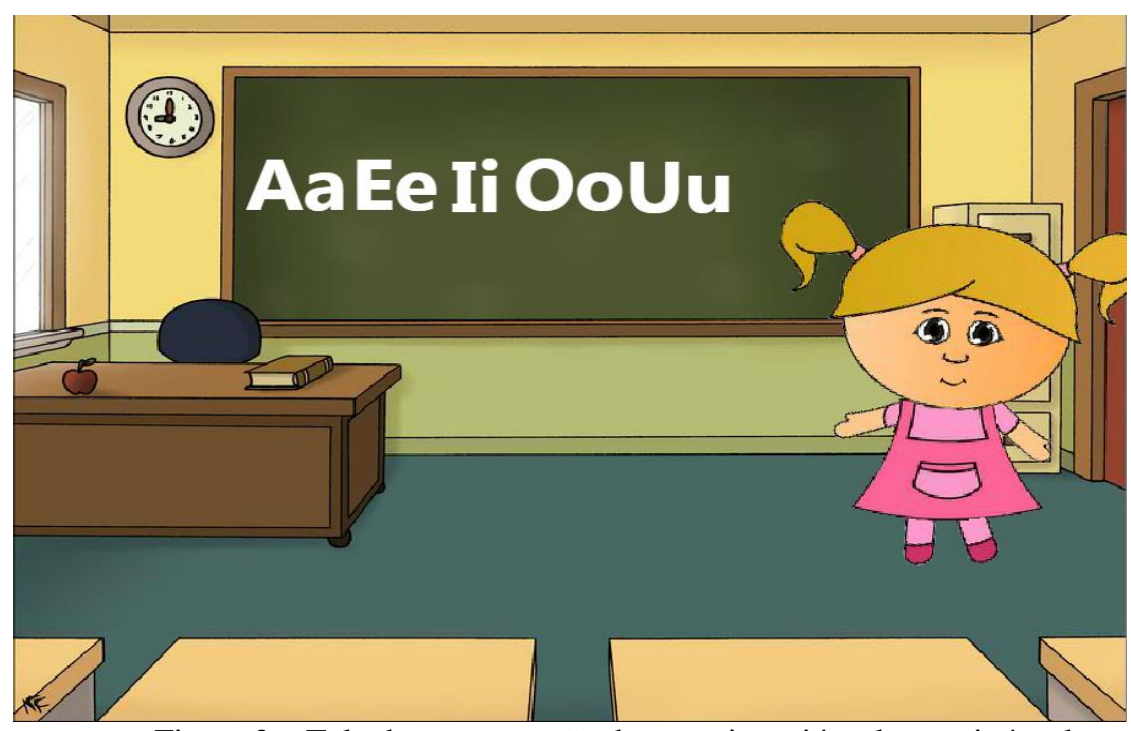

Figura 2 - Tela de apresentação das vogais maiúsculas e minúsculas

Para cada atividade ou jogo, a criança pode voltar, repetir, avançar ou sair.

$\mathrm{O}$ primeiro jogo tem como objetivo ligar as vogais maiúsculas com as minúsculas correspondentes. A Figura 3 exibe ao jogador, caso ele acerte a ligação, um rosto alegre no lado direito da tela.

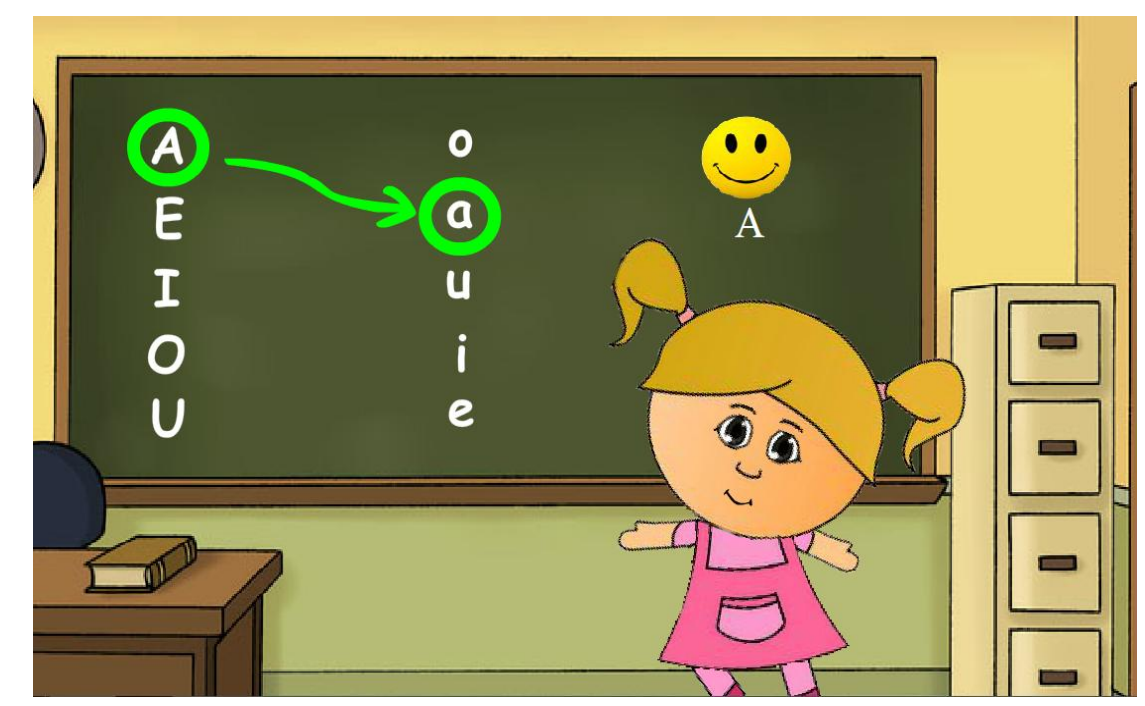

Figura 3 - Tela que liga as vogais maiúsculas com as vogais minúsculas

Se o usuário errar, nesse mesmo local aparece um rosto triste, com uma pista, para reforçar a resposta correta, que é a vogal correta. Em todos os jogos têm-se o mesmo feedback. Esse reforço é proposto por Kirk e Gallagher (1991).

A Figura 4 mostra o segundo jogo no qual o jogador tem que "clicar" no alto falante para ouvir o som da vogal e depois selecionar a vogal correspondente ao som. 


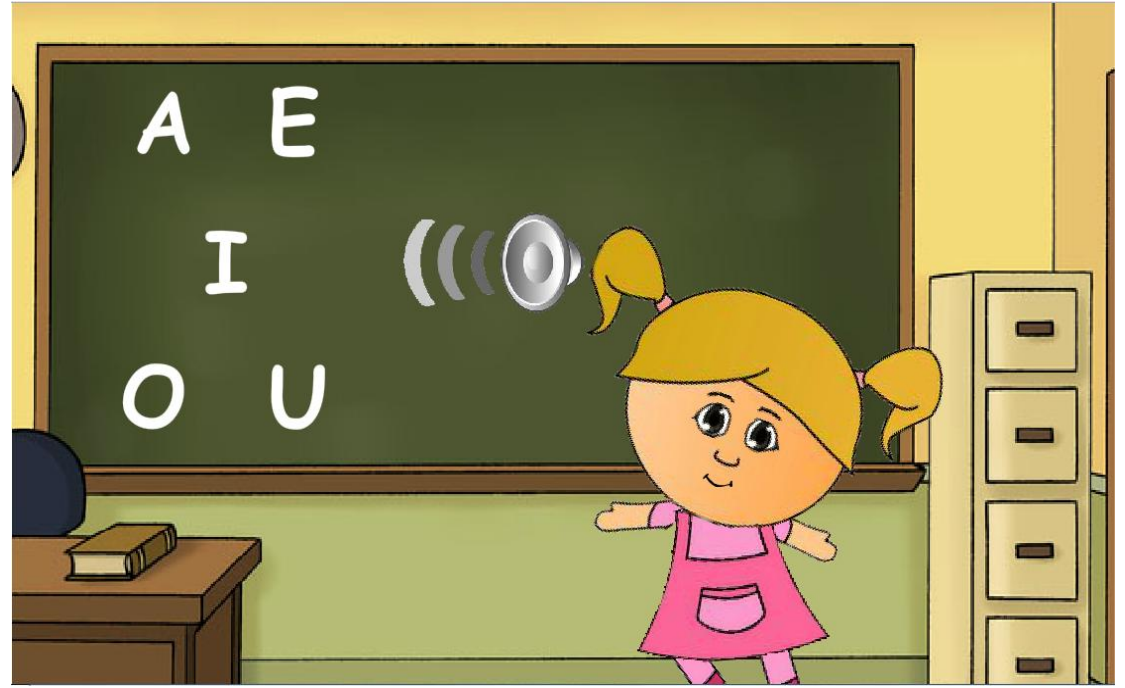

Figura 4 - Tela para identificar as vogais por meio do som

A Figura 5 apresenta o terceiro jogo no qual a criança terá que ligar as figuras com as suas respectivas vogais iniciais. Se o jogador errar a ligação, a seta ficará em vermelho e aparecerá uma cara triste no lado direito da tela.

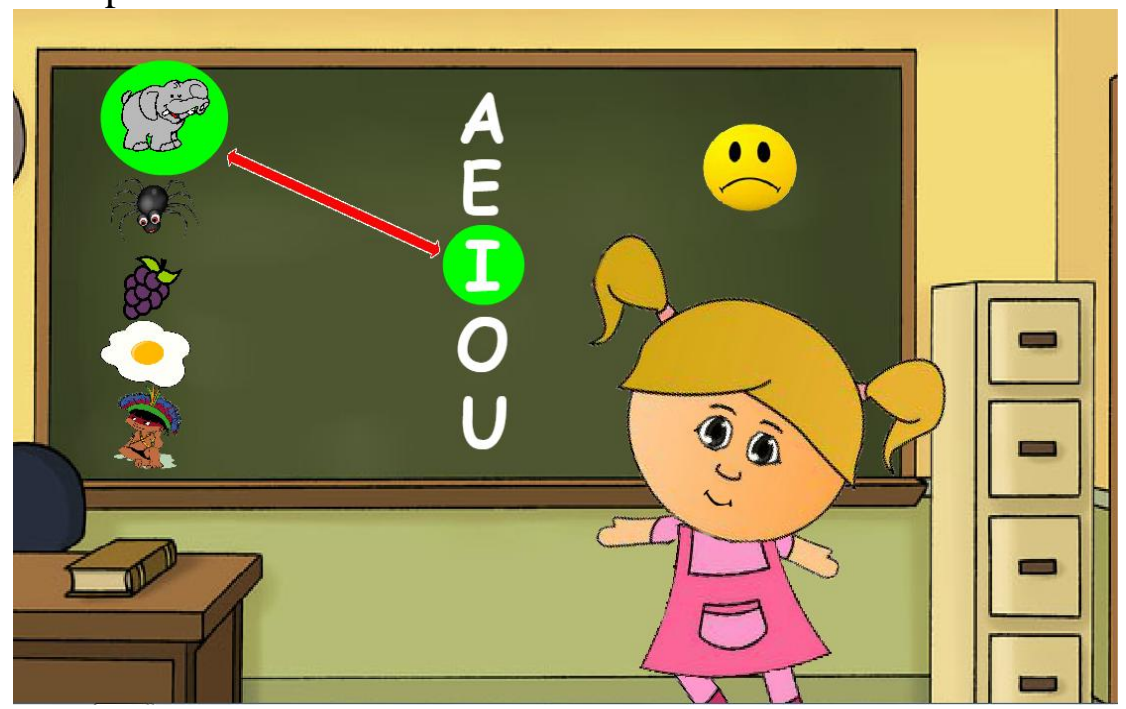

Figura 5 - Tela para ligar as figuras com as suas respectivas vogais iniciais.

$\mathrm{O}$ quarto jogo tem a função de encontrar as vogais usando o mouse e no lado direito é exibida a quantidade de acertos e erros, como ilustra a Figura 6. 


CINTED-UFRGS Novas Tecnologias na Educação

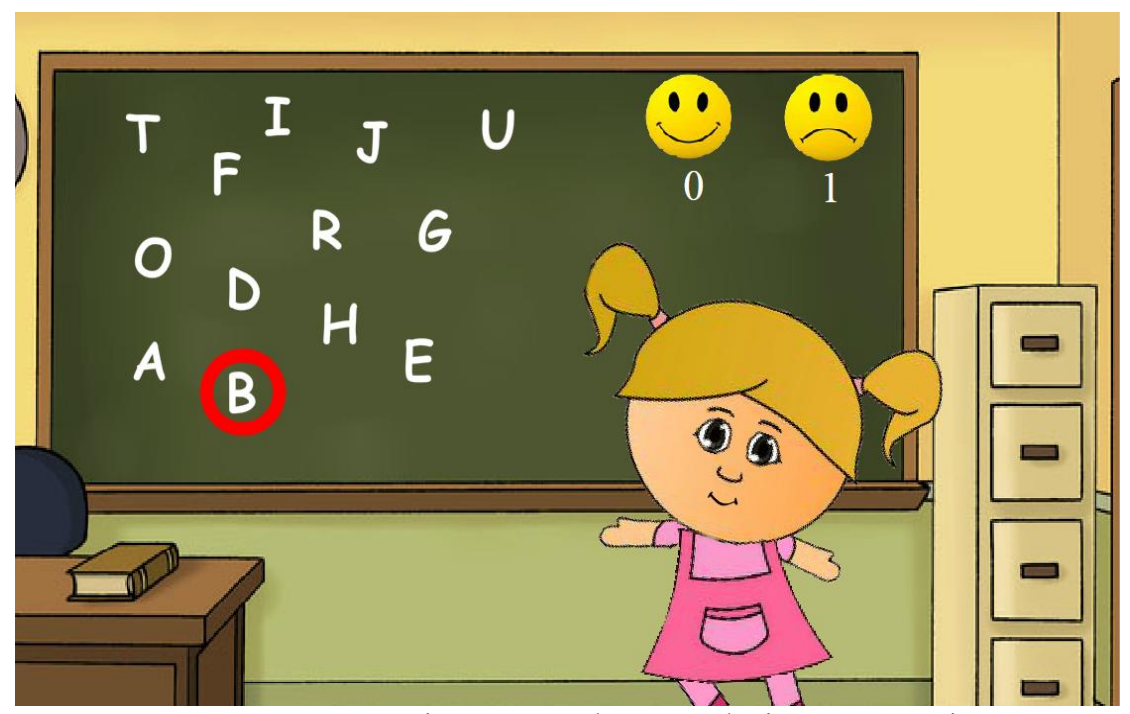

Figura 6 - Tela para selecionar as vogais.

A Figura 7 exibe o último jogo no qual o jogador deve digitar a vogal inicial de cada figura e clicar na mesma. Neste exemplo, digitou-se a letra errada da palavra Igreja e o feedback padrão foi mostrado.

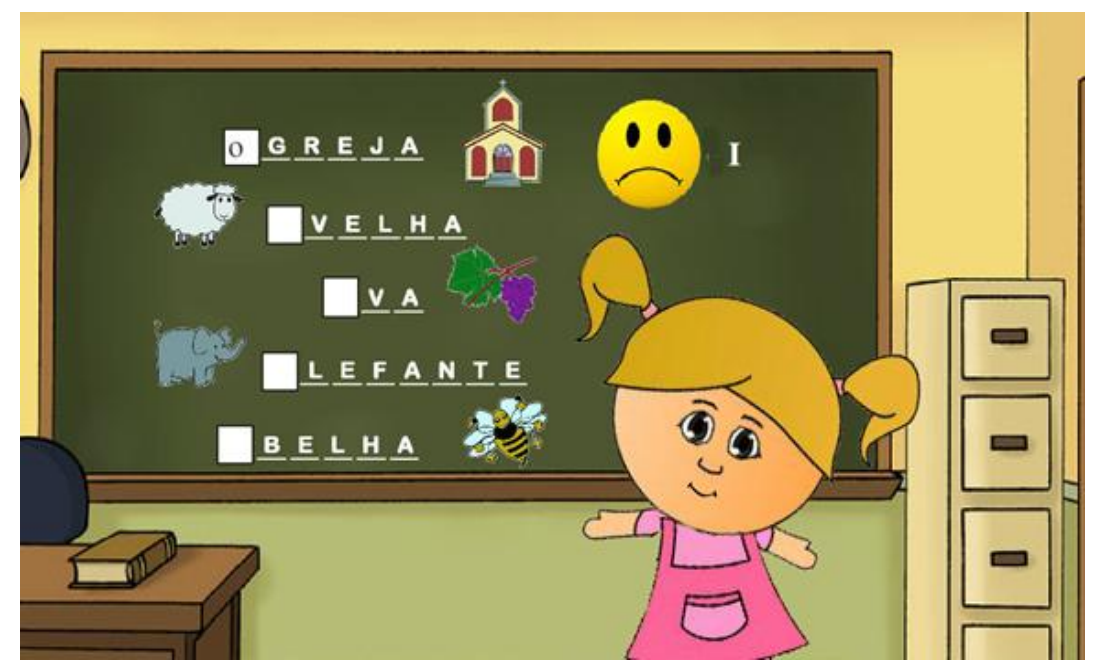

Figura 7 - tela em o jogador deve digitar a vogal inicial de cada figura

Aplicação e avaliação

Quanto às questões, 92,86\% (26 professores) responderam que o programa possui instruções claras. Em relação à facilidade de navegação, 100\% (28) disseram que apresentou. Descreveram que os jogos foram mostrados de forma lúdica $100 \%$ dos participantes e que o objetivo proposto foi atingido $92,86 \%$ (26). Relataram que havia correção das tarefas e feedbacks dos erros, $100 \%$ e que ele não era constrangedor ao aluno $92,86 \%$ (26). Especificaram que o programa apresentou acessibilidade para pessoas com Síndrome de Down, 85,71\% (24) e que a criança pode identificar quando errou ou acertou uma atividade, $82,14 \%$ (24). Responderam também que o software pode complementar as explicações das aulas $100 \%$. 
Descreveram que a forma das apresentações das vogais foi muito boa, 35,71\% (10); boa, 39,29\% (11); regular, 17,86\% (5) e deficiente, $7,14 \%$ (2) e que o software pode tornar o aprendizado mais motivador, $96,43 \%$ (27).

$\mathrm{Na}$ questão dissertativa $53,58 \%$ (15) colocaram seus comentários sobre o programa. Foram computados esses comentários e as respostas obtidas foram: não apresentar as vogais minúsculas, pois o aluno pode ficar confuso, por não ser ensinado isso nas aulas, 46,67\% (7); mostrar os conteúdos de forma mais lenta para que o aluno possa identificar as vogais, 6,67\% (1); apresentar o feedback em áudio e não apenas por meio de imagens, $13,33 \%$ (2); muito boa as atividades por meio de jogos, 6,67\% (1); existência de vários graus de Síndrome de Down e por isso, não pode ser aplicado a todos, mas apenas aos que têm conhecimento de cores, $20 \%$ (3) e exibir as vogais no início do programa acompanhadas de uma figura que representa a letra inicial da imagem, 6,67\% (1).

\section{Conclusão}

O objetivo desse trabalho foi criar, aplicar e avaliar um software educativo que ensine as vogais para pessoas com Síndrome de Down. Em relação à criação, foram identificadas as necessidades e os requisitos para atender ao público escolhido. O roteiro foi desenvolvido e foram criados 5 jogos. Foram utilizados os princípios de desenvolvimento de Engenharia de Software, sendo desenvolvida primeiramente a documentação do software, o roteiro e a codificação em Flash. Na aplicação da ação educativa, os professores responderam um questionário e foi possível a tabulação dos dados para a avaliação do software. Nesse contexto, os objetivos foram atingidos, pois todos os procedimentos foram realizados com êxito.

Os resultados, obtidos de forma qualitativa, trouxeram informações importantes para o uso do programa junto ao público alvo.

Todos os participantes disseram que o programa apresentou facilidade de navegação, como também descreveram que os jogos foram mostrados de forma lúdica. Esses aspectos são importantes para pessoas com Síndrome de Down, já que podem facilitar o aprendizado, tornando-o motivador.

Todos os professores também descreveram que havia correção das tarefas e feedbacks dos erros, e que ele não provoca constrangimento.

Outro aspecto especificado é que a grande maioria achou que o programa apresentou acessibilidade para pessoas Down.

Os participantes descreveram que a forma das apresentações das vogais foi em geral boa. Na questão dissertativa, praticamente a metade dos participantes comentaram que as vogais minúsculas não deviam ser apresentadas.

Também foi escrito nessa questão que os conteúdos podem ser exibidos de forma mais lenta para que o aluno possa identificar as vogais com maior facilidade.

Dessa forma, propõe-se fazer alterações no programa, retirando as vogais minúsculas e o jogo referente a esse conteúdo, como também apresentar as vogais de forma mais lenta na tela do computador.

Outra medida cabível é apresentar o feedback em áudio também e não apenas por meio de imagens, como foi desenvolvido.

Conclui-se pelos relatos dos professores que existem vários graus de Síndrome de Down e por isso, não pode ser aplicado a todos, mas para aqueles que têm conhecimento das cores e vogais, sendo o software um programa de apoio para as aulas dos professores. 


\section{Referências}

AMARAL, M. A.; GOMEDI, G. Desenvolvimento de Software Educacional para Crianças Portadoras de Síndrome de Down. In: Congresso Brasileiro de Computação, 4, 2004. Rio Grande do Sul, Anais... Rio Grande do Sul, 2004.

ARAÚJO, A. L. S. O; BRITO, R. R.; SILVA, A. P. Softwares para educação inclusiva: uma revisão sistemática no contexto de SBIE e WIE. In: Congresso Brasileiro de Informática na Educação, 2, 2013. Campinas, Anais... Campinas, 2013.

BISSOTO, M. L. Desenvolvimento cognitivo e o processo de aprendizagem do portador de Síndrome de Down: revendo concepções e perspectivas educacionais. Ciência \& Cognição, v. 4, p. 80-88, 2005. Disponível em:

<http://cienciasecognicao.org/revista/index.php/cec/article/view/485/262>. Acesso em: 25 jul. 2016.

CENCI, D.; BONELLI, S.M.S. Critérios para avaliação de software educativo. In: ANPED SUL, 9, 2012. Caxias do Sul, Anais... Rio Grande do Sul, 2012.

CERRO, M. D. Conceptos básicos sobre el cálculo: sumar y restar son medios para resolver los problemas de la vida diária. Fundación Síndrome de Down de Cantabria, 2006.

KIRK, S. A.; GALLAGHER, J.J. Educação da criança excepcional. São Paulo: Martins Fontes: 1991.

RODRIGUES, O. M. P.; SANTOS, L. H. Z.; CARLINO, F.C., Intervenção em habilidades sociais com uma criança com Síndrome de Down. Revista Educação Especial, v. 27, n. 48. p. 95-110, 2014. Disponível em:

<http://periodicos.ufsm.br/index.php/educacaoespecial>. Acesso em: 25 jul. 2016.

SILVA, C. R.. Bases Pedagógicas e ergonômicas para concepção e avaliação de produtos educacionais informatizados. Dissertação (Mestrado) Departamento de Engenharia da Produção. Universidade Federal de Santa Catarina, 1998.

SOARES, M. M. Computar na Educação Especial: a tecnologia no processo de desenvolver competências nas pessoas com necessidades educativas especiais. Itajaí, 2002.

VALENTE, J. A. Diferentes usos do computador na educação. Em aberto. n. 57. p. 316, 1993. Disponível em:

<http://www.rbep.inep.gov.br/index.php/emaberto/article/view/1876/1847>. Acesso em: 20 jul. 2016.

VIEIRA, F. M. S. 2012. Avaliação de software educativo: reflexões para uma análise criteriosa. Disponível em: <http://edutec.net/Textos/Alia/MISC/edmagali2.htm〉.

Acesso em: 28 jul. 2016. 